\title{
The Construction of Analysis Model for Sports Soft Power and Its Driving Mechanism
}

\author{
Jin Xiaojiao ${ }^{1, \text { a }} \quad$ Chu Lihui $^{2, \text { b }}$ \\ ${ }^{1,2}$ Xingtai Medical College, Xingtai, Hebei $054000, P R$, China \\ a,bjinxiaojiao_1980@sina.com
}

\begin{abstract}
Keywords:Sports soft power, Coupling structure model, National soft power, Driving mechanism
\end{abstract}

\begin{abstract}
This paper, through a large number of data and cases, analyses and expounds the role of sports soft power in that of state, and on the basis of erection of coupling structure model for the sports soft power, analyses and constructs the structure model of national soft power and sports strength as well as puts forward the corresponding control over the construction mechanism of soft strength in accordance with the significance and impact of culture , concept and system on the sports and national soft power so as to enhance China’s sports and national influence.
\end{abstract}

\section{Introduction}

Sports soft power has become an increasingly hot topic of people, which is mainly because, on the one hand, soft power has been drawing universal attentions in the theoretical field due to its growing strength in the context of global informatization[1,2] ; on the other hand, China is now on its way for a great sports power from a big sports country after the success of Beijing Olympic Games. Sports soft strength not only serves as an important part of China's soft power but also even the one of great sports power, and therefore, to enhance the construction of China's sports soft power will generate the significance for whether the raising and development of China soft power or the construction of great sports power and harmonious society. In the mid-1980s, China conducted the research on the index system of sport with some findings[3], among them, the system of China in question, designed in accordance with the basic model of "investment -activity- output", is comprised of three major categories and twenty sub-categories with total 200 indexes of statistics featuring in scientific design and clear structure, which makes it possible for us to well know and assess the development level of China's sports undertaking in an all-round way. As soft and hard power both serve as the parts of the completely comprehensive strength, people are attaching increasing importance to the soft strength, and the comprehensive power of national sport should consist of the soft and the hard , which is the organic combination of the two in question. Sports soft strength serves as the strong support for the formation and expansion of its hard one and an invisible power applied to everything and working at any time, which defines the concept of national sports soft power in theory, and we should, based on the concept, construct macro structure model of soft power for China's sports undertaking and probe into its driving mechanism , which has demonstrable and actual significance in formulating the development strategy of sports undertaking and the realization of being a great sports power from a big one.

Discrimination and Analysis of China's Sports Soft Power:The soft power of a state reflects the comprehensive strength exercised by a country against its citizens and other countries, and its core consists of values, sports system, sports spirit, national sports awareness and professional ethics of athletes and referees, audience's features and qualities and the passion and level of voluntary service, and so on. The complexity and illegibility of sports soft strength determines that the research on its contents shall be conducted only in a general perspective so as to avoid the issue of difficulty in carrying out the research on the soft power resulted from missing of key factors. Joseph Nye points out that the soft power consists of three aspects, namely, political values, appeal of culture and foreign policies. Sport, as a special cultural phenomenon in the society, involves all aspects of the society, and therefore, the soft power of sport should also cover the contents of each 
field of soft power, namely, its core contents are comprised of sports concept, system and culture. These three contents are not the ones with clear line classified as per the same standard, but the ones that enjoy different focuses, and they interweaved each other when expounding the sports soft power. Sports concept means the sports values, which gradually takes shape during people's long-term sports practices `and witnesses a long process of formation and development, so it enjoys long duration and serves as the foundation of soft power, which determines the others aspects of soft power. Sports system and structure, a code of conduct and operational mechanism, is formulated, in accordance with the general development laws of sport and the historical experience obtained from people's long-term engagements in sports activities, in order to standardize the behaviors that people participate in the sports and better promote the advance of sports undertaking. It, from an aspect, reflects the development level of a country or a region and serves as the guarantee of the expansion in the sports undertaking. It, in its own country, embodies in the appeal to the public, the participation of the masses and the prosperity of sports undertaking while it shows in the leadership of spots activities, disclosure right in the activities and the consistency level with state's foreign policies. The scope of sports culture covers widely, which means that all the cultural forms related to sport are in the category of sport culture and focuses on the contents about penetration and appeal generated in the sports activities. In a word, sports concept, system and structure are all under the sports culture.

Sports system, a regulation and code of conduct, is formulated in order to smoothly complete the sports tasks or target, and it shall embody the fairness and feasibility. The superiority of a country or a region's sports system and structure has a subliminal impact on other countries or regions and attracts them to imitate the system and structure, and then shows the appeal of actor of this system and structure in the field so as to achieve the end of carrying forward the cultural connotation followed by the actor, which is the very embodiment of sports soft power. No matter the capacity and talent or the civilization and quality showed in the sports activities all are the accumulation and deposit of daily education, which is an embodiment of cultural essence of this society and a representation of sports soft power. In the process of sports activities, the management level of a manager, professional ethic of a referee and the attitude of an attendant towards service and the mood of an audience are the major embodiments of sports soft power. In a word , the behaviors emerges in the sports activities should not only seek for the realization of sports goals but also contribute to the construction of humanity, which should not meet the moral norm of its nation and show the features in culture of its own country but also adapts to the demands of foreign nations for the culture.

For sports culture, the ideologies and behaviors of sports participants reflect the social and cultural environment they live, and the erection of good individual image is equal to show the excellent national culture of its own. With the gradual emergence of unique role in the sport, all countries actively push their own ethnic sports events to the world and meanwhile the sports culture like sports concept and fashion is also spread, and then we can achieve the goal of erecting good national image and spreading national culture, which serves as one of major channels to manifest national culture. We can deem the sports culture as the carriers of spreading the values, mechanism and system of our own nation to achieve the goal of building good national image and raising the international status, which is the very embodiment of sports soft power. Sports culture serves as part of social one and an important resource of sports soft power.

Analysis of model construction of sports soft power:The power consists of three key factors of resources, namely, sports culture, concept and system, which don't play a role alone in the actual operation but interact and interpenetrate by means of some coupling mechanism, and therefore, sports soft power shows the complicated structure of non-linearity, and the each resource couples with another one in the three key factors and forms the driving system for the three sports soft powers. Now the model of sports soft power designed in this paper shown as the illustration 1 


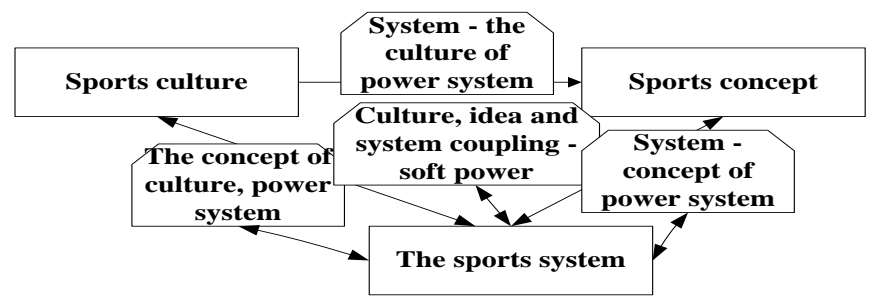

Illustration1. Theory model of coupling structure for national sports soft power

In this illustration, the sports soft powers are classified into three levels: it is made up of surrounding soft powers (including culture-idea, culture and metropolis, idea and system), coupling soft power and core soft power. In this soft power system, the coupling soft power at the middle level not only integrate the three key factors of soft power but also serves as the foundation of core soft power, and therefore, it is taken as the basic frame of analyzing the driving mechanism of sports soft power.

Here what needs emphasizing is although the relations between sport and national soft power are expounded, the culture mentioned in the theory of Joseph Nye inherit out of question the cultural outlook of Taylor, especially the acquisition of capacity, including sports, this idea serves as the premise of erecting his theory. But unfortunately, the domestic documents in relation to national power only apply Taylor's theory mechanically, holding that the development of soft power in culture (exclusive of sports) is equal to enhance the national soft power, which is the universal misunderstanding and will be no help for us to have knowledge of the national soft power as well as mislead us in the practice. Historical experience indicates: before the reform and opening-up, China had been facing the tough ride that had neither hard power nor soft one like diplomacy and special culture to carry out foreign exchange, but sports took the reasonability of diplomacy, serving as the new force of national soft power. If it failed to employ diplomatic means of sport in a smart way to give a full play of the guiding role of sport as national soft power, China would not have possibility of obtaining relatively safe international environment and creating favorable conditions for the future reform and opening-up. Sports' importance and contribution to the development of national soft power is beyond question and it integrates with national soft power in an organic way by means of the disclosure right in the international sports organizations as an intermediate variable. See Illustration 2.

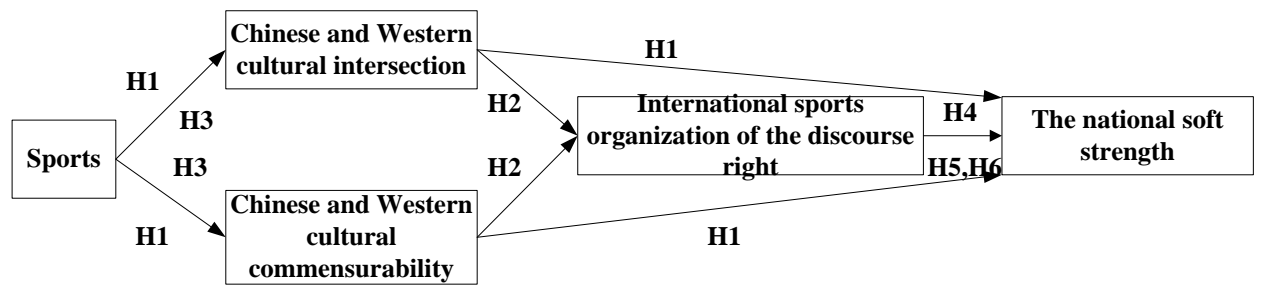

Illustration 2 Relations between the soft powers of sport and state

Relations between the soft powers of sport and state are clearly showed in the illustration , among them , internationally sports organization serves as the intermediate variable and the factors impacting the discourse right of the organization are mainly comprised of claim of national interests, innovation of sports concept, reform of sports system, the internationalization level of non-profit sports organization and the number of talents that is up to the position of the internationally sports organization as well as the relations between the soft powers of sport and state, which are described directly as the below model shown in illustration 3: 


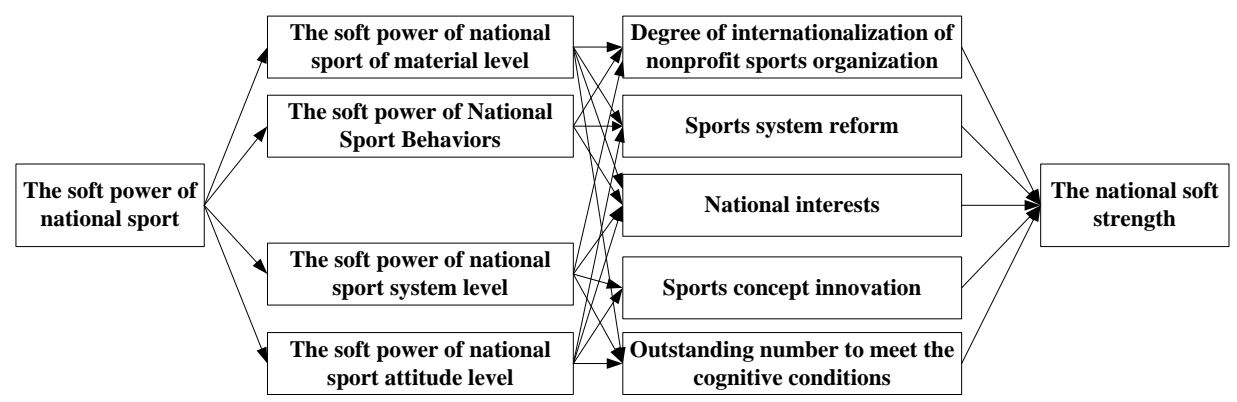

Illustration 3 Model of national sports soft power and structure model of sports soft model

\section{Analysis of driving mechanism of sports soft power}

Construction of the value for sports soft power:Concept instructs the action of practice and determines its orientation and result. The formation of concept has a close bearing on the cultural awareness and cultural identity, which are embodied in the importance universally attached to the cultural power in the relevant research on soft power. Sport exists as a kind of culture and naturally, its cultural power shall not be ignored, the role of the power in question is just like the concept of human, and therefore, first of all, it should boast attraction, and then it enables other countries and regions to be willing to imitate, follow and transform their values. The real problems of value system of Chinese traditional sport don't lie in itself, but in the incommensurability of its exchanges with other cultures, which makes it difficult to be accepted and transformed by other sports value systems in the world, this call for us to conduct the systematic and intercultural transformation as per the scientific principle and unearth and refine the accessible values.

Scientific outlook on development of sports is quite important and its basic meanings consist of the comprehensiveness of the development plan of soft power, the balance of development and the sustainability development. Sports values and sports outlook on development are the two powers that closely links with each other, the former determine the outlook on development while the development status of sports undertaking react to the formation of the latter on the whole, China's sports undertaking enjoys a good momentum of development, nationwide body-building plan and the program of striving for Olympic glory represent are its two major development orientations , and China's educational policy also places sports education on its higher agenda.

Analysis of the erection of innovated policy in culture:A state's sports system serves as an important premise that determines the basic development orientation, size and pace of sports undertaking and its formation, development, maturity and decline depend on the objective law of sports development, which is not changed by human will. China's competitive sports adopt the development model with "the whole national system" as its core. Under the circumstance of weak national strength of China, the implementation of the system in question rapidly erected the leading role in both Asia and the world, for a developing country with vulnerable foundation and large population, which is a pioneering work. China, after returning to the big sports family, has broken world record many a time and won the world champion again and again, which all resulted from the system.

Driving mechanism of concept and system:The updating of concept is the premise for the system reform while it ensures the actual realization of concept, and the interaction of the two factors in question determines the development of sports undertaking. Each sport concept can be deemed as a value system, among them, one value serves as the core for sure, namely core value. From the angle of the construction of national sports soft power, we should erect relatively complete sports concept system and its corresponding core value system. In accordance with the essence features of China's political system and sports undertaking, whose core value and its corresponding concept as the below: sports concept with the core value that aims to strive for national interests.

Through the holding of major international events of competitive sports, we can fully show the city image of our own, enhance the international popularity, and by means of which we can promote 
the urban construction, development and prosperity. if a city that can successfully hold a major competivite sports event in the world , the its public effect or even that of a state will be heightened considerately while international attention aroused by the event will serve as the invisible value of the city and the state in question. For example, the artistic performance in the opening ceremony of Beijing Olympic Games attract 40 billion audiences and live ones all over the world and show them Chinese ancient civilization and excellent traditions with the history covering 5000 years, expressing China's concept of peace development. The former Australian premier Kevin Michael Rudd once said: Beijing Olympic Games is a major event that marks China's integration into the big family of the world.

\section{Comclusions}

Largely, sports soft power is about the development and perfection of sports system. At the period of social transition, for the construction of China's sports soft power, it should give full play to creative power of sports values and the guiding role of sports outlook on development, which serves as the premise, and take the construction of great sports power as a goal and strengthening the construction of modern sports system as the core content of sports system so as to make full use of driving force of system's operation , the innovative power of system's reform and binding force of system and norm. promoting the development in a coordinated, comprehensive and sustainable way is the basic value orientation of the construction of sports system ; perfecting the legal system of sports system serves as the guarantee of the construction of sports system; building the national sports undertaking with proper structure and full range of function serves as the key point of the construction of sports system; the functional switching of government at the period of transition serves as the impetus for the system construction. The enhancement of sports soft power contributes to the raising of comprehensive national strength. Although sport is a kind of social culture, it has close connections with politics and economy. The development of sports undertaking and the enhancement of sports soft power will be a boost to the construction of a state's politics, economy and culture, and then improve the comprehensive national strength.

\section{References}

[1] Chen Kaihua . The construction of China's competitive sports soft power in the context of globalization [J]. Journal of Physical Education [J].2013.20(4):42-46.

[2] Cheng Linlin. The thinking about developing national sports power [J]. Journal of Sports and Science.2012, 33(5): 1-5.

[3] Zhong Guangfa. The incommensurability between the Chinese canonical forms and the ones of linguistics in the research on translation. [J]. Journal of Tianjin Foreign Studies Univeristy .2011,(03):36.

[4] Wang Zhongjie. The logic level and enhancing channel of sports soft power. [J] Journal of Physical Education, 2013, (5):4-5.

[5]Huang li. Research on the sports spirit of Chinese nation [M]. Beijing : Beijing Sport University Press, 2008: 202.

[6]Cheng qi, Yang Wenxuan, Liu Haiyuan et al . Research on China's modern sports values [J]. Sports and Science, 2006, 26(8): 3-9.

[7] She Yanli On the influence of sports soft power on China's construction of great sports power from the angle of stakeholders [J]. Sport Science and Technology .2014,45(22):82-85.

[8]Ma Meiying. Multi-dimensional research on the soft power of sports culture [J]. Journal of Wuhan Sports University ,2014,5 (2): 11-15.

[9] Cui Dongxia. Research on the impact of sports soft power on enhancing urban strength — - take Zhengzhou for example [J].Journal of Anhui Sports Science, 2014, (2):117-119.

[10]Du Guangyou. Carry forward and spread nation's traditional sports culture and raise its soft power of culture [J]. Journal of Harbin Institute of Physical Education, 2014, (2):25-27. 